

University of Pretoria

University of Pretoria

Department of Economics Working Paper Series

Inflation and Economic Growth in Latin America: Some Panel TimeSeries Evidence

Manoel Bittencourt

University of Pretoria

Working Paper: 2010-11

April 2010

Department of Economics

University of Pretoria

0002, Pretoria

South Africa

Tel: +27 124202413 


\title{
Inflation and Economic Growth in Latin America: Some Panel Time-Series Evidence*
}

\author{
Manoel Bittencourt ${ }^{\dagger}$
}

April 30, 2010

\begin{abstract}
In this paper we investigate the role of poor macroeconomic performance, in terms of high rates of inflation, in determining economic growth in four Latin American countries between 1970 and 2007. The empirical results, based on the relatively novel panel time-series analysis, confirm the anecdotal evidence which suggests that inflation has had a detrimental effect to growth in the region. All in all, we highlight the costs that inflation has had on economic activity, and also the importance of particular economic institutions which were implemented in the 1990s - central-bank independence and fiscal responsibilities laws - in actually keeping inflation under control in the region, as a first step in the direction of sustained growth and prosperity.
\end{abstract}

Keywords: Inflation, Growth, Latin America.

JEL Classification: E31, O11, O42, O54.

${ }^{*}$ I thank seminar participants at Pretoria and Wits for comments.

${ }^{\dagger}$ Department of Economics, University of Pretoria, Lynnwood Road, Pretoria 0002, RSA, e-mail: manoel.bittencourt@up.ac.za. 


\section{Introduction and Motivation}

Latin America has been known for its display of high rates of inflation, and even bursts of hyperinflation, in particular during its political transition in the 1980s and in the first half of the 1990s, and also for presenting erratic economic growth rates during roughly the same period of time. Some of the countries following this, somehow destructive, pattern include; Argentina, Bolivia, Brazil and Peru. In most of these cases, macroeconomic stabilisation took some time to take root, in fact stabilisation came only in the middle of the 1990s with the implementation of particular economic institutions, when, coincidentally enough, growth rates also started showing a positive trend.

Given this background, we investigate the role of the poor macroeconomic performance seen in the 1980s and early 1990s, in terms of high inflation rates, in determining economic growth in the region. More specifically, we use data from Argentina, Bolivia, Brazil and Peru from 1970 to 2007, and the relatively novel panel time-series analysis to study whether inflation played any role in growth in Latin America at the time or not.

The empirical results robustly suggest that, during the period investigated, inflation has not only been the main macroeconomic determinant of growth in the region, but also that its effect has been clearly a negative one on growth. It is therefore fair to say that the lack of certain economic institutions (i.e., central-bank independence and fiscal responsibility laws), instruments which were implemented in the region only in the second half of the 1990s, facilitated the process of generating easy money used to fund spiralling public deficits, which eventually led to those hyperinflationary bursts in the region with all their consequences on economic welfare ${ }^{1}$.

In addition, the importance of acquiring a better understanding of the hyperinflationary episodes of the past is not only because we currently have a protracted hyperinflationary event in Zimbabwe, with all its consequences on economic activity and welfare, but also because there is an ongoing debate in countries like South Africa and Argentina on the role and efficacy of

\footnotetext{
${ }^{1}$ For instance, Bittencourt (2009) investigates the case of the Brazilian hyperinflation of the 1980s and 1990s, and he suggests that the high rates of inflation seen at the time contributed to increase earnings inequality. Moreover, Easterly and Fischer (2001) suggest that the poor from 38 countries consider inflation to be a more pressing problem than the rich, which suggests that the poor are the ones suffering more with higher inflation.
} 
independent central banks in conducting monetary policy.

The contribution of this paper to the literature is that, firstly, we follow the advice given by Fischer (1993) and restrict our sample to those Latin American countries which suffered hyperinflationary episodes and erratic growth in the 1980s to conduct a more disaggregated case study on the subject. Secondly, we make use of principal component analysis to get independent variables with more explanatory power in an attempt to reduce model uncertainty. Thirdly, we also follow the advice given by Bruno and Easterly (1998) and make use of high-frequency data, without the usual averaging, to better pinpoint the effects of inflation on growth. Finally, we take advantage of the novel panel time-series analysis, and explore the cross-sectional and time-series variation in the data, so that we are able to provide more reliable and informative estimates on the topic.

The remainder of the paper is as follows: the next subsection briefly reviews and inserts this paper within the previous literature. Section Two describes the data and the empirical strategy used, and then reports and discusses the results obtained. Section Three concludes the paper, it summarises the work, and then it suggests some policy implications and also some possible future work.

\subsection{Related Literature}

De Gregorio (1993) presents some early evidence using a panel of twelve Latin American countries during the 1950-1985 period, and he suggests that inflation is detrimental to economic growth; and Fischer (1993) presents international cross-sectional and panel data evidence to suggest that inflation outweights the Mundell-Tobin effect. It is worth noting that, given the date of their publication, these two studies do not account for the hyperinflationary episodes in Latin America of the early 1990s, which would certainly reinforce their results.

Furthermore, Barro (1995) makes use of cross-sectional analysis, and he suggests that the high-inflation countries in his sample drive the negative effects of inflation on growth; and Bullard and Keating (1995) make use of VAR analysis to reach a similar conclusion (i.e., that in the high-inflation country in their sample, inflation negatively affects growth).

Moreover, Clark (1997) confirms the above and suggests that there are problems with cross-section regressions - because of the averaging - and that 
panel analysis might be the way forward; and Bruno and Easterly (1998) suggest that, because of the averaging again, there is no long-run relationship between inflation and growth when using cross-sectional analysis. Nevertheless, they suggest that there is a negative relationship between inflation and growth when inflation reaches their proposed $40 \%$ threshold.

In addition, Sarel, Gosh and Phillips, and Khan and Senhadji (1996, 1998 and 2001 respectively) confirm the above negative relationship between inflation and growth once inflation reaches particular thresholds. More recently, Sirimaneetham and Temple (2009) make use of an index for macroeconomic instability, based on principal component analysis, and Bayesian Model Averaging to deal with model uncertainty, and they suggest that macroeconomic stability is a necessary condition for economic growth in a panel of developing countries.

Ultimately, the literature suggests that high inflation is detrimental to growth (i.e., it either outweights the Mundell-Tobin effect, or it contributes to increased macroeconomic uncertainty which negatively affects investment and consequently growth), and in a region like Latin America-which has suffered from chronic income inequality - high inflation and erratic growth certainly display negative effects on overall economic welfare ${ }^{2}$.

Therefore, it is fair to say that this paper is a natural development of the previous literature on the subject (i.e., we conduct a case study that pinpoints in more detail the effects of severe macroeconomic instability on economic activity, we avoid the averaging and make use of annual data and panel time-series analysis so that we are able to capture more accurately the role of the macroeconomic volatility seen at the time in Latin America on growth, and we attempt to reduce model uncertainty via principal component analysis). It is therefore believed that we are able to provide informative estimates so that our knowledge on those historical episodes are somehow deepened.

\footnotetext{
${ }^{2}$ Other major contributions include Barro (1997), Easterly (2001), Fischer (2004) and Easterly (2005), not to mention the numerous growth studies which include inflation as the main proxy for macroeconomic stability. Overall, most of these studies reach the conclusion that macroeconomic instability is detrimental to economic growth. Alternatively, see Temple (2000) for an early survey of the literature.
} 


\section{Data, Empirical Strategy, and Results}

The data set used covers the period between 1970 and 2007, and four Latin American countries, namely Argentina, Bolivia, Brazil and Peru (i.e., $T=38$ and $N=4)$. The growth rates of the real gross domestic products per capita (GROW) are provided by the Penn World Table (PWT) data set mark 6.3, and the data on inflation (INFLAT) come from the Bureaux of Census of the four countries.

The control variables used include the government's share in the real GDP (GOV), which proxies for the size of government, the ratio of exports and imports to real GDP (OPEN), as a proxy for economic openness, and the ratio of investment to real GDP $(I N V)$, all from the PWT files. We also use a measure of financial development (i.e., the ratio of the liquid liabilities to GDP (M2)) from the World Bank's World Development Indicators (WDI).

Moreover, we interact the average years of schooling of those aged 25 and over (from the Barro and Lee data set) with the percentage of the total urban population (from the WDI files) to construct an index for structural development $(D E V)$, which is supposed to capture the fact that more developed societies tend to be not only more educated, but also more urbanised.

Furthermore, via spectral decomposition we are able to extract the unobserved common factors of three normalised Polity IV variables (i.e., democracy (DEMOC), constraints on the executive (XCONST), and political competition $(P O L C O M P)$ ), so that we end up with a proxy for political regime characteristics $(P O L)$ which contributes to reduce model uncertainty, and that presents more explanatory power. Basically, this proxy captures the role of the political transitions taking place in Latin America in the 1980s.

Finally, we also extract the unobserved common factors amongst inflation, government's share in the real GDP and the ratio of external debt to GDP, and construct an index for macroeconomic stability $(S T A B I L)$, which contributes to reduce the dimensionality of a set of prospective cyclical macroeconomic variables, and that presents more explanatory power.

For the sake of clarity, in Figure One we plot the data on GDP per capita and inflation rates in Argentina, Bolivia, Brazil and Peru respectively, and what we can see is that during the hyperinflationary bursts of the 1980s, GDP per capita presented sharp decreases in all four countries, just to recover after the stabilisation of the 1990s. 

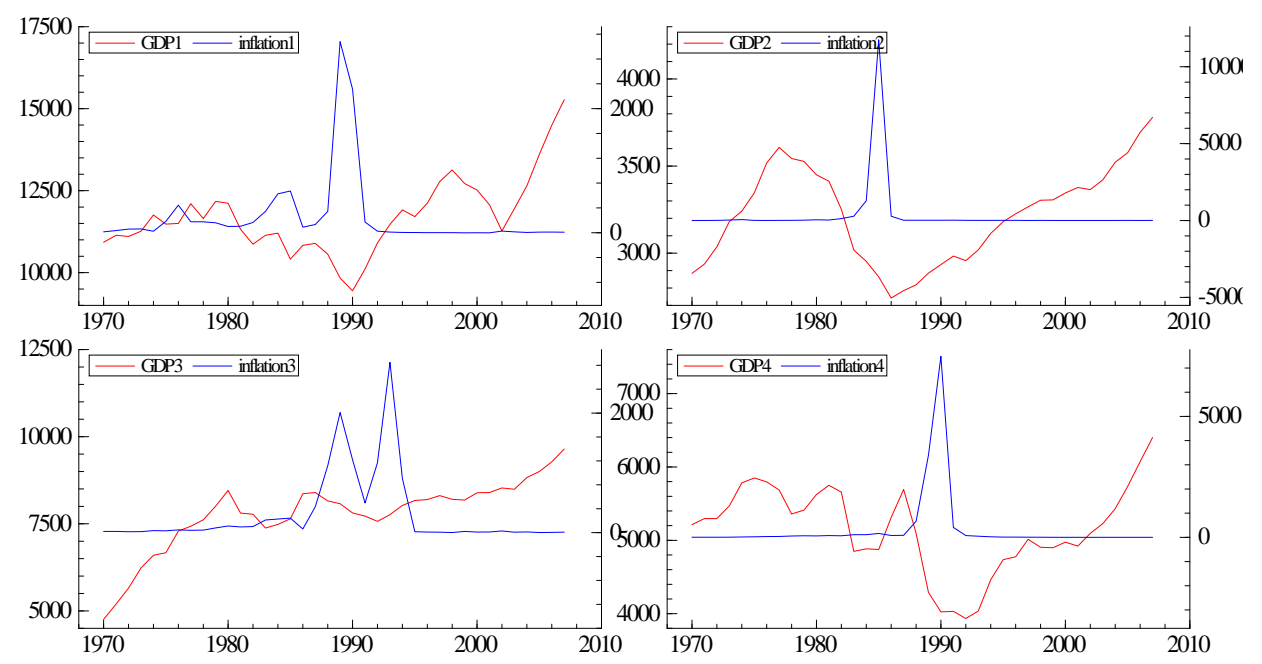

Figure 1: GDP per capita and Inflation, Argentina, Bolivia, Brazil and Peru, 1970-2007. Sources: Penn World Table and Bureaux of Census. GDP is the GDP per capita and Inflation is the inflation rate.

Moreover, in Table One we present the correlation matrix of the variables used, and inflation and growth present negative and statistically significant correlations to each other. The control variables present the expected signs (i.e., bigger governments are known to be detrimental to growth, more open economies tend to grow faster, investment, for being one of the main components of GDP, is positively correlated to growth, and the measure of financial development is positively correlated to growth as well as our measure of development). Finally, the variable of political regime characteristics indicates that the implementation of democracy in the region in the 1980s, which is illustrated by a reduction in the index $P O L$, was, in fact, detrimental to growth in the region ${ }^{3}$.

\footnotetext{
${ }^{3}$ Bittencourt (2010) suggests that, because of the distributional conflict and some populist tendencies, some of the Latin American countries that transitioned from dictatorship to democracy in the 1980s suffered from severe macroeconomic instability at the time.
} 
Table 1: The Correlation Matrix: Argentina, Bolivia, Brazil and Peru, 1970-2007.

\begin{tabular}{lrrrrrrrr}
\hline \hline & GROW & INFLAT & GOV & OPEN & INV & M2 & DEV & POL \\
\hline GROW & 1 & & & & & & & \\
INFLAT & $-.451^{*}$ & 1 & & & & & & \\
GOV & $-.166^{*}$ & $.333^{*}$ & 1 & & & & & \\
OPEN & .044 & $-.379^{*}$ & $-.633^{*}$ & 1 & & & & \\
INV & $.244^{*}$ & -.118 & .105 & $-.434^{*}$ & 1 & & & \\
M2 & .104 & $-.299^{*}$ & $-.165^{*}$ & $.368^{*}$ & $-.277^{*}$ & 1 & & \\
DEV & .017 & -.056 & -.141 & .077 & $.334^{*}$ & .019 & 1 & \\
POL & .100 & -.142 & $.227^{*}$ & $-.323^{*}$ & $.379^{*}$ & $-.423^{*}$ & $-.384^{*}$ & 1 \\
\hline \hline
\end{tabular}

Sources: Penn World Table, Bureaux of Census, World Development Indicators, Barro and Lee, and Polity IV. ${ }^{*}$ represents significance at the $5 \%$ level.

Furthermore, in Figure Two we plot the OLS regression lines between inflation and growth in Argentina, Bolivia, Brazil and Peru respectively, and in all four countries the relationship is negative and statistically significant, which indicates that perhaps there is an economic relationship between these two variables.

All in all, this initial inspection of the data, with all its caveats, suggests that the anecdotal evidence of high inflation rates and erratic economic growth in Latin America might well be correct (i.e., the data plots show the sharp decline in income during the hyperinflationary bursts, the statistical correlation between inflation and growth is negative and significant, and finally the OLS regression lines indicate a significant negative economic relationship between inflation and growth in the region). 

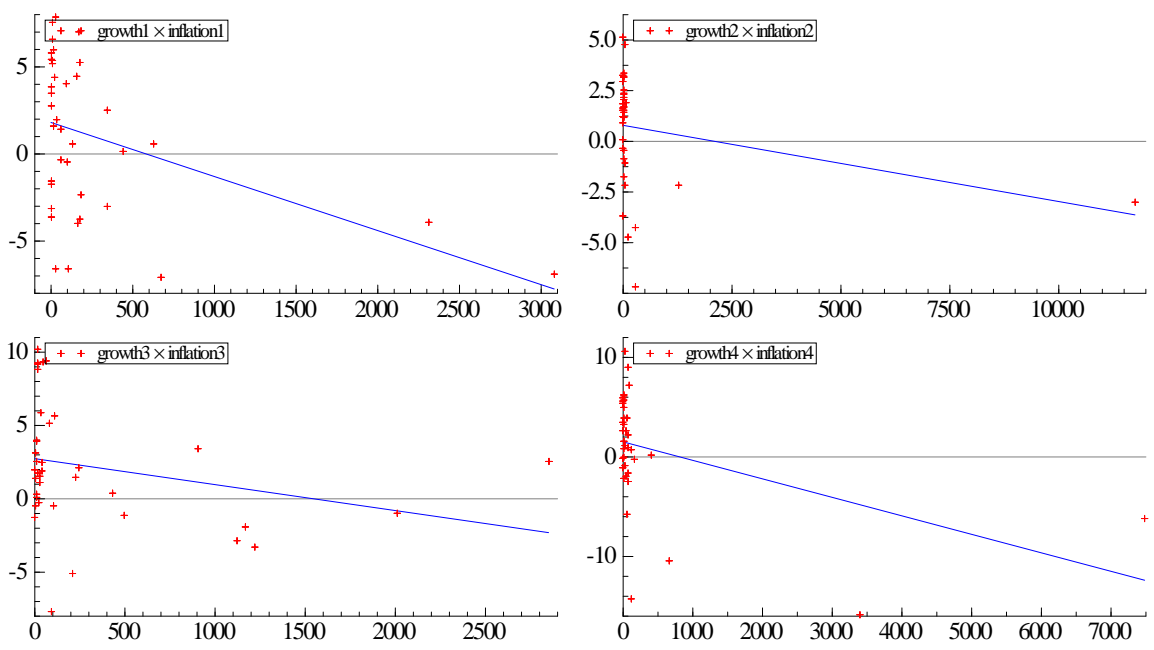

Figure 2: OLS Regression Lines between Growth and Inflation, Argentina, Bolivia, Brazil and Peru, 1970-2007. Sources: Penn World Table and Bureaux of Census. $G$ row $t h$ is the GDP growth rate and Inflation is the inflation rate.

In terms of econometric modelling, since we have a $T>N$ data set, the empirical strategy used is based on the relatively novel panel time-series analysis. Firstly, for non-stationarity in the country time-series we use the Im, Pesaran and Shin (IPS (2003)) test, which allows for heterogeneous parameters and serial correlation. The IPS test consists of an augmented Dickey-Fuller regression for each variable of each country, and these are then averaged. The moments of the mean and variance of the average $\bar{t}$ are -1.46 and .63 respectively ${ }^{4}$.

Secondly, the issue of heterogeneity bias in dynamic $T>N$ panels, which is caused because, under wrongly assumed homogeneity of the slopes, the disturbance term is serially correlated and the explanatory variables $x_{s}$ are not independent of the lagged dependent variable $y_{t-1}$. This is dealt with by the Swamy's (1970) Random Coefficients (RC) estimator, which gives consistent estimates of the expected values ${ }^{5}$. Moreover, the one-way Fixed

\footnotetext{
${ }^{4}$ An alternative to IPS (2003) is the test by Levin, Lin and Chu (2002). However, this test assumes parameter homogeneity, and therefore does not consider a possible heterogeneity bias present in the data.

${ }^{5}$ The Mean Group estimator, proposed by Pesaran and Smith (1995), is also an alternative. However, this estimator is sensitive to outliers, a problem not faced by the RC estimator.
} 
Effects (FE) estimator also provides consistent estimates in dynamic models when $T \rightarrow \infty$, but only when the slopes are homogeneous ${ }^{6}$.

All in all, these two estimators account not only for an important econometric issue in dynamic $T>N$ panels, but also for the fact that some of these countries present different levels of economic development and sophistication (e.g., Brazil and Argentina are known to be relatively more developed than Peru and Bolivia).

Furthermore, some would justly argue that there is reverse causality present (i.e., that higher growth is actually generating higher inflation and not the inverse). We therefore use the Fixed Effects with Instrumental Variables (FE-IV) two-stage Least Squares estimator, with the index STABIL as our identifying instrument for inflation. This index is believed to capture the role of the unobserved common factors amongst inflation, government size and external debt in, actually, predicting inflation. The estimates provided by the FE-IV estimator are asymptotically consistent and efficient as $T \rightarrow \infty$.

We therefore estimate static and dynamic models with different pooled estimators (i.e., the benchmark Pooled Ordinary Least Squares (POLS), Fixed Effects, Random Coefficients and Fixed Effects with Instrumental Variables estimators), so that different econometric issues are dealt with and more reliable estimates provided ${ }^{7}$. The estimated heterogeneous dynamic equation is therefore as follows,

$$
\begin{aligned}
\text { GROW }_{i t}= & \alpha_{i}+\beta_{i} I N F L A T_{i t}+\gamma_{i} G O V_{i t}+\delta_{i} O P E N_{i t}+\epsilon_{i} I N V_{i t} \\
& +\varepsilon_{i} M 2_{i t}+\zeta_{i} D E V_{i t}+\eta_{i} P_{i t}+\theta_{i} G R O W_{i t-1}+v_{i t}
\end{aligned}
$$

in which GROW are the growth rates of the domestic GDPs, INFLAT are the inflation rates, GOV is the share of government in the GDP, OPEN is a measure of economic openness, $I N V$ is the share of investment to GDP, $M 2$ is the share of the liquid liabilities to GDP, $D E V$ is the interaction term between education and urbanisation, and $P O L$ is the political regime variable which consists of the common factors of DEMOC, XCONST and POLCOMP.

\footnotetext{
${ }^{6}$ In addition, GMM-type estimators are not an alternative under $T>N$ for the overfitting problem. See Bond (2002).

${ }^{7}$ Zellner (1969) states that for static models all panel estimators give unbiased estimates of the expected values.
} 
In addition, we deal with between-country dependence, which is believed to happen through the disturbances being $E\left(v_{i t} v_{j t}\right) \neq 0$. Given the nature of the data, we make use of Zellner's (1962) Seemingly Unrelated Regressions (SUR) estimator, which presents greater efficiency, the greater the correlation amongst the disturbances. The SUR estimates different country time series, which are then weighted by the covariance matrix of the disturbances ${ }^{8}$. Moreover, this estimator provides rather insightful estimates because it disaggregates the analysis even further than the pooled analysis, so that we can have a more in-depth view of the effects of the hyperinflationary processes on growth in the region ${ }^{9}$. Equation Two illustrates the equation estimated for each country,

$$
\begin{aligned}
G R O W_{t}= & \alpha_{t}+\beta I N F L A T_{t}+\gamma G O V_{t}+\delta O P E N_{t}+\epsilon I N V_{t} \\
& +\varepsilon M 2_{t}+\zeta D E V_{t}+\eta P O L_{t}+\theta G R O W_{t-1}+v_{t}
\end{aligned}
$$

In terms of results, firstly, in Table Two we report the IPS statistics, and they suggest that we can reject the null hypothesis of unit roots and accept in favour of the alternative that at least one variable of each country is, in fact, stationary. With that in mind, we do not have to incur in any further data transformation, nor pursue cointegration analysis.

\footnotetext{
${ }^{8}$ An alternative to SUR is the Common Effects Estimator proposed by Pesaran (2006). However, $N$ is assumed to be large and in our data set $N=4$. Furthemore, Kapoor, M., H. H. Kelejian, et al. (2007) propose an estimator that also works best under the $N \rightarrow \infty$ assumption.

${ }^{9}$ For a more thorough discussion about panel time-series analysis in general, see Smith and Fuertes (2008) or Lee, Pesaran and Smith (1998).
} 
Table 2: Panel Unit-Root Tests

\begin{tabular}{lc}
\hline \hline Variables & IPS Statistics \\
\hline GROW & -3.241 \\
INFLAT & -2.871 \\
GOV & -3.134 \\
OPEN & -2.512 \\
INV & -2.415 \\
M2 & -2.042 \\
DEV & -2.188 \\
POL & -2.262 \\
\hline \hline
\end{tabular}

The moments of the mean $E$ and variance var of the average $\bar{t}$ are respectively: -1.43 and .62. Source: Im, Pesaran and Shin (2003) and author's own calculations.

Secondly, in Table Three we report the static and dynamic estimates of INFLAT on GROW using the POLS, FE and RC estimators respectively. All four estimates of INFLAT are negative and statistically significant against GROW. GOV presents mostly negative and significant estimates, which confirms the fact that bigger governments tend to be detrimental to economic growth. $I N V$, as expected, presents positive and mostly significant effects on $G R O W$. The other control variables do not present clear-cut estimates in this instance. Moreover, the $\mathrm{F}^{*}$ test indicates that there is evidence of regional fixed effects and the Likelihood Ratio (LR) test suggests heterogeneity of intercepts and slopes, which indicates that the FE is the most appropriate estimator in the static case, and the $\mathrm{RC}$ the most appropriate one in the dynamic case. 
Table 3: POLS, FE and RC Estimates of Inflation on Economic Growth, 1970-2007.

\begin{tabular}{lrr|rr}
\hline \hline & \multicolumn{5}{c}{ Static and Dynamic Models } \\
\cline { 2 - 5 } GROW & \multicolumn{1}{c}{ POLS $(1)$} & FE $(2)$ & \multicolumn{1}{c}{ FE $(3)$} & \multicolumn{1}{c}{ RC $(4)$} \\
\hline INFLAT & $-2.16(-4.97)$ & $-1.90(-4.46)$ & $-1.64(-3.71)$ & $-1.71(-2.37)$ \\
GOV & $-.1385(-1.14)$ & $-.4023(-2.42)$ & $-.3987(-2.42)$ & $.0625(.14)$ \\
OPEN & $-.0368(-1.08)$ & $.0430(.49)$ & $.0092(.11)$ & $.1597(.88)$ \\
INV & $.2353(2.29)$ & $.3165(2.93)$ & $.2926(2.51)$ & $.2247(.56)$ \\
M2 & $.0054(.17)$ & $-.0361(-.95)$ & $-.0339(-.90)$ & $-.0734(-.51)$ \\
DEV & $-.0035(-1.47)$ & $-.0097(-1.20)$ & $-.0060(-.74)$ & $-.0266(-.74)$ \\
POL & $-.3096(-1.11)$ & $-.4095(-1.29)$ & $-.3674(-1.17)$ & $-.7463(-1.26)$ \\
GROW $t-1$ & & & $.1313(1.56)$ & $.0595(.41)$ \\
F test & 7.38 & 9.49 & 8.93 & \\
F test* & & 4.88 & 3.97 & \\
R $^{2}$ & .26 & .16 & .23 & \\
LR test & & & & \\
Wald test & & & & \\
\hline \hline
\end{tabular}

T-ratios in parentheses. Number of observations: $N T=152$. The basic estimated equation is $G R O W_{i t}=\alpha_{i}+\beta_{i} I N F L A T_{i t}+\gamma_{i} G O V_{i t}+\delta_{i} O P E N_{i t}+\epsilon_{i} I N V_{i t}+$ $\varepsilon_{i} M 2_{i t}+\zeta_{i} D E V_{i t}+\eta_{i} P O L_{i t}+\theta_{i} G R O W_{i t-1}+v_{i t}$, in which $G R O W$ is the growth rate of the real GDP, INFLAT is the inflation rate, GOV is the government's share in the real GDP, $O P E N$ is a measure of economic openness, $I N V$ is the investment ratio to real GDP, $M 2$ is the liquid liabilities ratio to real GDP, $D E V$ is the interaction of schooling and urbanisation, and $P O L$ is a proxy for political regime characteristics. POLS is the Pooled Ordinary Least Squares, FE is the Fixed Effects and RC the Random Coefficients estimators.

Thirdly, in Table Four we report the static and dynamic estimates of INFLAT on GROW using the FE-IV estimator, and all INFLAT estimates are negative and statistically significant in this case too. GOV confirms the fact that bigger governments tend to be detrimental to growth, and $I N V$ confirms its positive and significant effect on growth. The other controls do not present clear-cut effects this time either. Furthermore, the identifying instrument, $S T A B I L$, is positive and statistically significant in the first-stage regressions, and the $\mathrm{F}^{*}$ test indicates evidence of country fixed effects. 
Table 4: FE-IV Estimates of Inflation on Economic Growth, 1970-2007.

\begin{tabular}{lr|r}
\hline \multirow{2}{*}{ GROW } & \multicolumn{2}{c}{ Static and Dynamic Models } \\
\cline { 2 - 3 } INFLAT & $-4.07(-2.58)$ & $-4.16(-2.11)$ \\
GOV & $-.323(-1.71)$ & $-.324(-1.71)$ \\
OPEN & $-.059(-.50)$ & $-.062(-.52)$ \\
INV & $.226(1.70)$ & $.236(1.85)$ \\
M2 & $-.072(-1.49)$ & $-.072(-1.37)$ \\
DEV & $-.008(-.97)$ & $-.008(-.98)$ \\
POL & $-.851(-1.84)$ & $-.865(-1.66)$ \\
GROW $t-1$ & & $-.022(-.15)$ \\
F test* & 2.26 & 2.42 \\
$\mathrm{R}^{2}$ & .23 & .23 \\
\hline \hline
\end{tabular}

T-ratios in parentheses. Number of observations: $N T=152$. The basic estimated equation is $G R O W_{i t}=\alpha_{i}+\beta I N F L A T_{i t}+\gamma G O V_{i t}+\delta O P E N_{i t}+\epsilon I N V_{i t}+$ $\varepsilon M 2_{i t}+\zeta D E V_{i t}+\eta P O L_{i t}+\theta G R O W_{i t-1}+v_{i t}$, in which $G R O W$ is the growth rate of the real GDP, INFLAT is the inflation rate, GOV is the government's share in the real GDP, $O P E N$ is a measure of economic openness, $I N V$ is the investment ratio to real GDP, $M 2$ is the liquid liabilities ratio to real GDP, $D E V$ is the interaction of schooling and urbanisation, and $P O L$ is a proxy for political regime characteristics. The identifying instrument is the variable $S T A B I L$. FE-IV is the Fixed Effects with Instrumental Variables estimator.

Finally, when we disaggregate the analysis further and make use of the SUR estimator that takes into account any between-country dependence present in the data, the story the data are telling us does not change much. In the first panel of Table Five INFLAT presents negative signs on growth and most of the static estimates are statistically significant. Most of the control variables do not present clear-cut estimates, although most $G O V$ estimates are negative, most $I N V$ estimates are positive, and most $M 2$ estimates are negative ${ }^{10}$. The Lagrange Multiplier (LM) test of independence suggests that we can not accept the null hypothesis of between-countries $\left[\right.$ in] dependence ${ }^{11}$.

\footnotetext{
${ }^{10}$ For instance, Rousseau and Yilmazkuday (2009) suggest that financial development does not play the expected positive role on growth in high-inflation countries.

${ }^{11}$ The IPS test reported in Table 2 above assumes the existence of between-country
} 
Furthermore, the second panel reports the dynamic estimates, and again INFLAT presents mostly negative and significant effects in growth. GOV and $I N V$ present their expected signs (i.e., bigger governments are detrimental to growth and investment has a positive effect in growth). The liquid liabilities $M 2$ present mostly negative effects, which is what is predicted in countries with high rates of inflation. The LM test of independence again suggests that we can not accept the null hypothesis of between-countries independence in this case either, which validates the use of the SUR estimator in this analysis.

It is worth saying that the only country not presenting statistically significant INFLAT estimates in this more disaggregated analysis is Argentina. Using the information in Figure One, this is certainly because GDP per capita and growth rates in Argentina were already experiencing negative trends from the late 1970s onwards, probably because of the excessive political instability seen at the time in that country. Nevertheless, during the hyperinflationary events of the 1980s income and growth suffered even sharper reductions than in the 1970s.

In addition, the SUR analysis highlights the fact that the countries in the sample have different economic characteristics (e.g., Argentina and Brazil already possessed in the 1980s a fairly sophisticated indexation mechanism, which could have minimised the welfare costs of inflation on economic activity). Nevertheless, inflation kept its detrimental effect to growth not only in less developed countries like Bolivia and Peru, but also to a fairly sophisticated economy like Brazil.

independence. An alternative that considers the existence of between-country dependence is proposed by Pesaran (2007), the cross-section IPS (CIPS) test. However, CIPS assumes that $N>10$ and we have $N=4$ in our data set. It is therefore thought that the IPS test in this case is slightly biased but still informative and the best alternative available. 
Table 5: SUR Estimates of Inflation on Economic Growth, 1970-2007.

\begin{tabular}{lrrrc}
\hline \hline & \multicolumn{5}{c}{ SUR } \\
\cline { 2 - 5 } GROW & ARGENTINA & \multicolumn{1}{c}{ BOLIVIA } & BRAZIL & PERU \\
\hline INFLAT & $-.9930(-.83)$ & $-.9596(-1.94)$ & $-2.61(-2.48)$ & $-4.63(-5.46)$ \\
GOV & $-.5975(-1.93)$ & $.0623(.19)$ & $1.09(1.77)$ & $-1.92(-3.22)$ \\
OPEN & $-.0779(-.19)$ & $.2443(2.37)$ & $.2642(.59)$ & $-.0650(-.35)$ \\
INV & $.8439(1.77)$ & $-.0639(-.41)$ & $.0099(.03)$ & $.3423(1.98)$ \\
M2 & $-.2828(-1.45)$ & $-.0405(-.57)$ & $.2172(2.39)$ & $-.2675(-1.77)$ \\
DEV & $-.0012(-.03)$ & $-.0056(-.22)$ & $-.0880(-2.07)$ & $-.0060(-.53)$ \\
POL & $-1.36(-2.67)$ & $.1784(.42)$ & $-1.13(-1.33)$ & $-1.06(-1.78)$ \\
LM test & 14.78 & & & \\
\hline INFLAT & $-1.35(-1.11)$ & $-.6259(-1.50)$ & $-2.39(-2.12)$ & $-5.20(-5.10)$ \\
GOV & $-.4750(-1.44)$ & $-.3126(-1.00)$ & $.9720(1.52)$ & $-1.91(-2.99)$ \\
OPEN & $-.0636(-.15)$ & $.1724(2.00)$ & $.1751(.36)$ & $-.1341(-.70)$ \\
INV & $.9922(1.80)$ & $-.0748(-.58)$ & $.1755(.42)$ & $.4486(2.32)$ \\
M2 & $-.3235(-1.61)$ & $-.0123(-.21)$ & $.1895(2.02)$ & $-.2720(-1.79)$ \\
DEV & $.0044(.09)$ & $-.0141(-.66)$ & $-.0707(-1.48)$ & $-.0028(-.25)$ \\
POL & $-1.53(-2.56)$ & $.1484(.40)$ & $-1.06(-1.18)$ & $-1.17(-1.94)$ \\
GROW $t-1$ & $-.1571(-.99)$ & $.2186(1.75)$ & $-.0135(-.09)$ & $-.1182(-.89)$ \\
LM test & 11.66 & & & \\
\hline \hline & & & & \\
\hline
\end{tabular}

T-ratios in parentheses. Number of observations: $N T=152$. The basic estimated equation is $G R O W_{t}=\alpha_{t}+\beta I N F L A T_{t}+\gamma G O V_{t}+\delta O P E N_{t}+\epsilon I N V_{t}+\varepsilon M 2_{t}+$ $\zeta D E V_{t}+\eta P O L_{t}+\theta G R O W_{t-1}+v_{t}$, in which GROW is the growth rate of the real GDP, INFLAT is the inflation rate, GOV is the government's share in the real GDP, $O P E N$ is a measure of economic openness, $I N V$ is the investment ratio to real GDP, $M 2$ is the liquid liabilities ratio to real GDP, $D E V$ is the interaction of schooling and urbanisation, and $P O L$ is a proxy for political regime characteristics. SUR is the Seemingly Unrelated Regressions estimator.

All in all, the estimates reported above indicate that the inflation rates clearly and robustly presented detrimental effects to economic growth in those Latin American countries which experienced bursts of hyperinflation during their political transitions in the 1980s. It is also worth highlighting that the only cyclical and structural variable presenting clear-cut effects in growth was, in fact, inflation, which suggests that macroeconomic performance, given its extreme nature, was the main driving force behind economic 
activity at the time in the region. Furthermore, although these countries stabilised their economies in the 1990s, the analysis conducted here highlights the negative effects of inflation on growth over the entire period. Finally, inflation did not discriminate between more and less developed economies in the region (i.e., all countries in the sample were affected by high inflation).

All the same, the above is potentially important in terms of economic welfare, the macroeconomic instability seen at the time in the region reduced growth, which usually has a first- and second-order impact on the poor via higher unemployment, and subsequently increased poverty and inequality.

\section{Concluding Observations}

We investigated in this paper the role of macroeconomic performance, in terms of inflation rates, in determining economic growth in a panel of Latin American countries that experienced hyperinflationary episodes in the 1980s and early 1990s. The results, based on the relatively novel panel time-series analysis, suggest that inflation was detrimental to growth in the region at the time. More specifically, amongst the cyclical and structural variables used in the regression analysis, inflation proved to be the only one presenting clearcut effects against growth, which highlights its central role in determining economic activity in the region. Moreover, although inflation has been under control in Latin America for some time, overall it still presents detrimental effects to economic activity, which highlights the importance of those hyperinflationary bursts in distorting economic activity in a diverse region that already suffers from, among other things, chronic income inequality.

The quality of the evidence presented is, to a certain extent, boosted not only because we focus on those countries which suffered from hyperinflation in Latin America, but also because we use a novel proxy for macroeconomic instability based on principal component analysis, which is believed to be a step forward since it reduces model uncertainty and has more explanatory power. Moreover, we avoid the averages and take advantage of the novel panel time-series analysis, which deals with important empirical issues not covered by the previous studies, such as heterogeneity bias in dynamic panels, economic endogeneity and between-country dependence. It is therefore believed that the analysis conducted here represents a step forward in terms of achieving better and more insightful estimates, and therefore in improving 
our knowledge on the subject.

The historical importance and topicality of carrying out a study on inflation and growth is that, firstly, as we speak a country like Zimbabwe has been experiencing a severe hyperinflationary episode for a rather prolonged period of time, with all its consequences on economic activity and welfare. Secondly, in a country like South Africa, which possess an independent central bank, there is an ongoing debate about the efficacy, and even legitimacy, of such an economic institution in conducting monetary policy and its impact on growth. Thirdly, Argentina has also recently been debating the role of its own central bank and governor in conducting monetary policy. Therefore, the lessons of past hyperinflationary episodes and their effects on economic activity must be not only learned and well understood, but also kept in the minds of policy makers and other stakeholders, so that the mistakes of the past are not repeated again.

Regarding future work, on the one hand the issues of nonlinearities and thresholds can be investigated. On the other hand, a comparison between the four Latin American countries studied here with the four Asian Tigers, which presented macroeconomic stability and fast economic growth, would certainly enrich this sort of analysis further; or a comparison between these four Latin American countries with some of the Eastern European transition economies, which also presented bursts of hyperinflation in the 1990s, would further our knowledge of inflation and growth, and also of the determinants of these distinct hyperinflationary episodes in these particular regions.

To conclude, the Latin American hyperinflationary experience is informative because it exemplifies an interesting pattern seen in the region at the time. Most Latin American societies that went through political transitions and which still did not have the right economic institutions such as an independent central bank conducting sound monetary policy and a credible fiscal authority in place, ended up experiencing traumatic episodes of hyperinflation, which affected mainly the welfare of the poor. Moreover, coincidentally enough, macroeconomic stabilisation came only when those countries introduced central bank independence, inflation targeting and fiscal responsibility laws in the $1990 \mathrm{~s}^{12}$.

\footnotetext{
${ }^{12}$ For instance, Singh (2006), Singh and Cerisola (2006) and Santiso (2006) highlight the importance of the much improved macroeconomic performance in Latin America recently to produce better economic outcomes from the 1990s onwards. Nevertheless, Carstens and Jácome (2005) warn that Brazil still has one of the least independent central banks
} 
Ultimately, the lesson here is that political liberalisation processes in developing countries should be accompanied by the implementation of the right economic institutions, so that the cost of generating high inflation is increased in the first place and macroeconomic factors do not become impediments to economic growth and prosperity.

\section{References}

[1] Barro, Robert J. 1995. Inflation and Economic Growth. In NBER Working Paper Series.

[2] Bittencourt, Manoel. 2010. Democracy, Populism and Hyperinflation[s]: Some Evidence from Latin America. In Working Papers 169, Economic Research Southern Africa, University of Cape Town.

[3] Bittencourt, Manoel. 2009. Macroeconomic Performance and Inequality: Brazil, 1983-94. The Developing Economies 47 (1):30-52.

[4] Bond, Stephen R. 2002. Dynamic Panel Data Models: A Guide to Micro Data Methods and Practice. Portuguese Economic Journal 1 (2):141-62.

[5] Bruno, Michael, and William Easterly. 1998. Inflation crises and longrun growth. Journal of Monetary Economics 41:3-26.

[6] Bullard, James, and John W. Keating. 1995. The long-run relationship between inflation and output in postwar economies. Journal of Monetary Economics 36:477-496.

[7] Clark, Todd E. 1997. Cross-country evidence on long-run growth and inflation. Economic Inquiry XXXV:70-81.

[8] Easterly, William. 2005. National Policies and Economic Growth: A Reappraisal. In Handbook of Economic Growth, edited by P. Aghion and S. N. Durlauf: Elsevier.

[9] Easterly, William, and Stanley Fischer. 2001. Inflation and the Poor. Journal of Money, Credit and Banking 33 (2):160-178.

[10] Fischer, Stanley. 1993. The role of macroeconomic factors in growth. Journal of Monetary Economics 32:485-512.

in Latin America. 
[11] Fischer, Stanley. 2005. IMF Essays from a Time of Crisis. The International Financial System, Stabilization, and Development: The MIT Press.

[12] Ghosh, Atish, and Steven Phillips. 1998. Warning: Inflation May Be Harmful to Your Growth. IMF Staff Papers 45 (4):672-710.

[13] Gregorio, José De. 1993. Inflation, taxation, and long-run growth. Journal of Monetary Economics 31:271-298.

[14] Im, Kyung So, M. Hashem Pesaran, and Yongcheol Shin. 2003. Testing for Unit Roots in Heterogeneous Panels. Journal of Econometrics 115 (1):53-74.

[15] Kapoor, Mudit, Harry H. Kelejian, and Ingmar R. Prucha. 2007. Panel Data Models with Spatially Correlated Error Components. Journal of Econometrics 140 (1):97-130.

[16] Khan, Mohsin S., and Abdelhak S. Senhadji. 2001. Threshold Effects in the Relationship Between Inflation and Growth. IMF Staff Papers 48 (1):1-21.

[17] Lee, Kevin, H. Pesaran, and R.P. Smith. 1998. Growth empirics: a panel data approach - a comment. Quarterly Journal of Economics 113:319323.

[18] Levin, Andrew, Chien-Fu Lin, and Chia-Shang James Chu. 2002. Unit Root Tests in Panel Data: Asymptotic and Finite-Sample Properties. Journal of Econometrics 108 (1):1-24.

[19] Pesaran, M. Hashem. 2006. Estimation and Inference in Large Heterogeneous Panels with a Multifactor Error Structure. Econometrica 74 (4):967-1012.

[20] Pesaran, M. Hashem. 2007. A Simple Panel Unit Root Test in the Presence of Cross Section Dependence. Journal of Applied Econometrics 27.

[21] Pesaran, M. Hashem, and Ron Smith. 1995. Estimating Long-Run Relationships from Dynamic Heterogeneous Panels. Journal of Econometrics 68 (1):79-113. 
[22] Rousseau, Peter, and Hakan Yilmazkuday. 2009. Inflation, financial development, and growth: A trilateral analysis. Economic Systems 33:310324 .

[23] Santiso, Javier (2006). Latin America's Political Economy of the Possible. Cambridge, MA, The MIT Press.

[24] Sarel, Michael. 1996. Nonlinear Effects of Inflation on Economic Growth. IMF Staff Papers 43 (1):199-215.

[25] Singh, A. (2006). Macroeconomic Volatility: The Policy Lessons from Latin America. IMF Working Paper.

[26] Singh, A., and M. Cerisola (2006). Sustaining Latin America's Resurgence: Some Historical Perspectives. IMF Working Paper.

[27] Sirimaneetham, Vatcharin, and Jonathan R. W. Temple. 2009. Macroeconomic Stability and the Distribution of Growth Rates. World Bank Economic Review 23 (3):443-479.

[28] Smith, Ron, and Ana-Maria Fuertes. 2008. Panel Time-Series. In London: Centre for Microdata Methods and Practice. Institute for Fiscal Studies.

[29] Swamy, P.A.V.B. 1970. Efficient Inference in a Random Coefficient Regression Model. Econometrica 38 (2):311-323.

[30] Temple, Jonathan. 2000. Inflation and Growth: Stories Short and Tall. Journal of Economic Surveys 14 (4):395-426.

[31] Zellner, Arnold. 1962. An Efficient Method of Estimating Seemingly Unrelated Regressions and Test for Aggregation Bias. Journal of the American Statistical Association 57 (298):348-68.

[32] Zellner, Arnold. 1969. On the Aggregation Problem: A New Approach to a Troublesome Problem. In Economic Models, Estimation and Risk Programming: Essays in Honor of Gerhard Tintner. K. A. Fox, et al. Berlin, Springer-Verlag: 365-378. 